\title{
Influence of the size of nanostructured metals on changes in the functional state of the cell and biological activity
}

\author{
Dmitry Churilov ${ }^{1}$, Gennady Churilov ${ }^{2}$, Svetlana Polischuk ${ }^{3,}$, , Veronika Churilova ${ }^{4}$, and \\ Darya Byshova $^{5}$ \\ ${ }^{1}$ Ryazan State Agrotechnological University, Road Transport Faculty, Department of Metal \\ Technology and Machine Repair, Kostychev street 1, 390044, Ryazan, Russia \\ ${ }^{2}$ Ryazan State Medical University, Faculty of Medicine, Department of General Chemistry, \\ Vysokovoltnaya street 9, 390026, Ryazan, Russia \\ ${ }^{3}$ Ryazan State Agrotechnological University, Faculty of Medicine, Kostychev street 1, 390044, \\ Ryazan, Russia \\ ${ }^{4}$ Ryazan State Agrotechnological University, Technological Faculty, Department of Selection and \\ Seed Production, Agricultural Chemistry, Forestry and Ecology, Kostychev street 1, 390044, Ryazan, \\ Russia \\ ${ }^{5}$ Ryazan State Agrotechnological University, Faculty of Vet Medicine and Biotechnology, Kostychev \\ street 1, 390044, Ryazan, Russia
}

\begin{abstract}
The properties of nanostructured metals differ from the classical ones. The biological activity of nanoparticles is influenced by many factors, but primarily by concentration and size. It is urgent to study their interaction with living organisms, in particular plants, for which the main action is the realization of the genetic orientation of various varieties and hybrids, as well as the enhancement of the biosynthesis of biologically active compounds. The same biological effects are caused by nanoparticles of the same size, although the magnitude of their activity is different. It is assumed that these effects are due to the action of a certain regulatory response signal in biological systems. One of the responses may be changes in the structure of membranes that allow the passage of nanostructured particles, which can contribute to a change in the functional state of the cell. The magnitude of the response signal depends on the concentration of nanoparticles. The aim of this work is to study the effect of the size of nanostructured metals of various concentrations on the change in the functional state of the cell and the manifestation of biocompatibility and bioaccumulation in relation to nanoparticles.
\end{abstract}

\section{Introduction}

For metals in the nanoscale state (nanoparticle size up to $100 \mathrm{~nm}$ ), an increase in the chemical potential of substances at the interface and a change in their chemical potentials are characteristic. Their significant specific surface area increases their adsorption capacity

\footnotetext{
* Corresponding author: svpolishuk@mail.ru
} 
and enhances their reactivity. Nanoparticles (NPs) in living systems have the ability to integrate into cellular structures, to bind to proteins and nucleic acids, changing the functions of these biostructures. High activity suggests the presence of properties of nanoparticles as adsorbents. All this indicates that nanomaterials can turn out to be a source of increased risk for living systems, or can be good as an energy component of growth and development processes.

Nanoparticles of metals and oxides with a size of 30-80 nm practically do not dissolve in water, however, they have a charge and high adhesion to plant material. It is believed that the interaction of nanoparticles with aqueous solutions is one of the factors of their biological activity due to their permeability through membranes. At the same time, the most diverse information of particles of different physical-chemical properties, sizes and concentrations can enter living systems.

The effect of low doses (LD) was revealed for nanoparticles, that suggests an oscillatory nature of the dose dependence and the presence of an interval between two peaks of biological activity, that is the "dead zone", where the activity is not manifested or decreases. This effect is due to the small size and wave nature of nanoparticles. One of the manifestations of stress exposure, including the effect of nanoparticles, is the presence of an adaptive response, which is a universal response of cells to an irritant in "small" doses, and the acquisition of resistance to the damaging effect of NPs in a "large" dose.

Possessing a high energetic effect, nanoparticles are able to stimulate membrane permeability and changes in supramolecular structures. They also increase the concentration of protons, enhancing the regenerative ability and accelerate the processes of extraction and energy storage [1-3]. In addition, there are data on parametric resonance, which is possible for insignificant concentrations of active substances, acting at the subcellular and cellular levels [4]. Nanoparticles binding to the target change their receptor conformation, forcing the enzyme to pass into an active nonequilibrium state. At a certain concentration, this stage leads to the maximum activity of enzymes, but up to a certain limit.

Thus, nanoparticles change step by step the spatial configuration of the supramolecular structures of the cytoplasm and the microenvironment of the cell, each of which is characterized by a certain action for biological activity and the course of the most important biochemical reactions [5].

\section{Materials and methods}

\subsection{Place and conditions of investigations.}

Laboratory investigations were carried out at the Center for Nanomaterials and Nanotechnologies for the Agro-Industrial Complex at Ryazan State Agrotechnological University Named after P.A. Kostychev. The studies concerned the effect of nanoparticles (NPs) of iron, copper, cobalt and zinc on growth and development of white mustard, wheat, corn and vetch. Nanoparticles of the following sizes were used: those of up to $20 \mathrm{~nm}$, the ones sized $30-80 \mathrm{~nm}$ and $100-200 \mathrm{~nm}$. The range of the studied concentrations was $0.001-$ $1,000.0 \mathrm{~g} /$ per ton of seeds. There were three replications. The research was carried out by the procedure [2].

The analyzed indicators included:

- germination on the $3^{\text {rd }}$ day;

- the height of shoots and roots on the $3^{\text {rd }}$ and $7^{\text {th }}$ day;

- activity of peroxidase, superoxide dismutase and catalase on the $10^{\text {th }}$ day;

- activity of phytohormones on the $30^{\text {th }}$ day.

A medium based on seaweed polysaccharide was used as a substrate. The number of seeds in each Petri dish was 50 pieces. 
On the $10^{\text {th }}$ day of germination, the tops and roots were separated and the activity of enzymes was determined and on the $30^{\text {th }}$ day of phytohormones. The content of endogenous samples was determined in one sample, separately for roots and shoots after weighing them. The material for biochemical analysis was the supernatant obtained after homogenization of the plant tissue.

Plant samples weighing $900 \mathrm{mg}$ were crushed in a porcelain mortar with the addition of $10 \mathrm{ml}$ of cold phosphate buffer solution $1 / 15 \mathrm{M} \mathrm{pH} \mathrm{6.7.} \mathrm{The} \mathrm{extraction} \mathrm{of} \mathrm{water-soluble}$ components was carried out for 1 hour at $4 \pm 2^{\circ} \mathrm{C}$. The obtained samples were centrifuged at $3,000 \mathrm{rpm}$ for $15 \mathrm{~min}$. A supernatant solution was used for analysis.

The activity of peroxidase was determined by the formation of colored products of the oxidation of benzidine under the action of an enzyme contained in plants. The activity of the enzyme was determined on a photoelectric colorimeter by the intensity of the blue color of the oxidation product (n, n'-diaminediphenylquinone).

The amount of superoxide dismutase was determined using a solution of quercetin. The optical density of the solution was measured at a wavelength of $406 \mathrm{~nm}$ immediately after addition and every $60 \mathrm{sec}$ for $10 \mathrm{~min}$ in comparison with a blank sample.

Catalase in plant tissues was determined by the rate of decomposition of hydrogen peroxide by catalase of the test sample. The reagents were sequentially introduced into the test samples: $30 \mu \mathrm{l}$ of the extract and $2.95 \mathrm{ml}$ of $50 \mathrm{mM}$ of the Na-phosphate buffer $(\mathrm{pH}$ 7.0). The reaction was started in each tube by adding $20 \mu \mathrm{l}$ of $0.6 \mathrm{M}$ hydrogen peroxide solution. The optical density of the solution was determined at a wavelength of $240 \mathrm{~nm}$ every second for $100 \mathrm{~s}$.

When determining the activity of phytohormones, the plant mass was filtered. The acidified aqueous residue was purified by extraction with hexane. The ethyl acetate extracts were evaporated to dryness, where gibberellic (GA), abscisic (ABA) and indoleacetic (IAA) acids were determined. The aqueous residue was brought to $\mathrm{pH} 8$ with $20 \%$ potassium hydroxide solution and evaporated to dryness, where cytokinins were determined. Phytohormones were determined by high performance liquid chromatography (HPLC).

\subsection{The method for assessing bioaccumulation and biocompatibility of nanoparticles in seedlings using electron microscopy.}

Nanostructured metals were obtained by chemical deposition of metal hydroxides from salt solutions followed by their low-temperature reduction with hydrogen at MISiS, Moscow. Using X-ray phase analysis on an XRD-7,000 diffractometer (Shimadzu), the phase composition was determined [6,7]. The specific surface area was measured by the method of low-temperature nitrogen adsorption by BET (Quantachrome NOVA 1,200e analyzer). Suspensions of nanoparticles were prepared in distilled water, dispersing with ultrasound for 10 minutes, $300 \mathrm{~W}$ at a frequency of $23.7 \mathrm{kHz}$. The resulting suspensions were used for seed treatment.

To characterize nanoparticles, especially when predicting the degree of accumulation and biocompatibility, it is necessary to know the degree of dissolution of solid nanoparticles in water and biological fluids, which facilitate the ingress and migration of their compounds in tissues and organs. When determining the solubility, suspensions of nanoparticles $(50 \mathrm{mg} / \mathrm{l})$ were kept at $37 \pm 0.5^{\circ} \mathrm{C}$ in a thermostat for the necessary time. At a certain interval, an aliquot was taken and centrifuged $(4,400 \mathrm{rpm}, 40 \mathrm{~min})$. The solution was separated from the solid phase. The concentration of copper, zinc and cobalt ions was determined in the solution using a PD-303 Apel spectrophotometer. Solubility values of nanoparticles, wt \% for sizes of 20-60 nm and up to $20 \mathrm{~nm}$ are shown in Tables 1 and 2. 
To determine the surface charge of nanoparticles, their motion in an electric field was studied. The experiment showed that most of the particle-aggregates had electric charges, mostly positive, but a small part had negative ones. Therefore, the charge was estimated by the ratio of positive, negative and neutral ones. The results are presented in the table.

Analysis of the distribution of metals in tissues of the studied plants and electron microscopic studies were carried out using a scanning microscope Neon 40 and Merlin (Carl Zeiss, Germany) according to the method [8], and a transmission electron microscope "JEOL" "JEM-1,400".

\section{Results}

The effect of nanostructured copper, cobalt, iron and zinc after seeds pretreatment on morphophysiological properties of agricultural plants (corn, vetch, wheat, mustard) was studied. Their high biological activity was determined at concentrations of $0.01-100 \mathrm{~g} / \mathrm{t}$ of seeds, while for all particles sized $30-80 \mathrm{~nm}$, the same regularity in their action and the presence of the "effect of low doses" were observed. At a concentration above $100 \mathrm{~g} / \mathrm{t}$, the dose-effect relationship ceased to appear, but all indicators of biological activity (germination energy, size and weight of shoots and roots of seedlings) remained significantly higher than the control, that is, there was no inhibition even at a concentration of $500 \mathrm{~g} / \mathrm{t}$ (Figures 1a, 2, 4a). Nanoparticles, exhibiting biological activity at the same size, showed a pattern of equal shape, but different in magnitude effect.

Nanoparticles of up to $20 \mathrm{~nm}$ exhibited the LD effect at low doses and only up to a concentration of $10 \mathrm{~g} / \mathrm{t}$. At a concentration of $100 \mathrm{~g} / \mathrm{t}$, all indicators for such sizes were lower than the control. Some inhibition of plant development was observed (Figures 1b, 3, 4b). Such nanoobjects were more soluble in water and biological fluids and exhibited biological activity in a narrow range of concentrations at the same high physical and chemical activity.

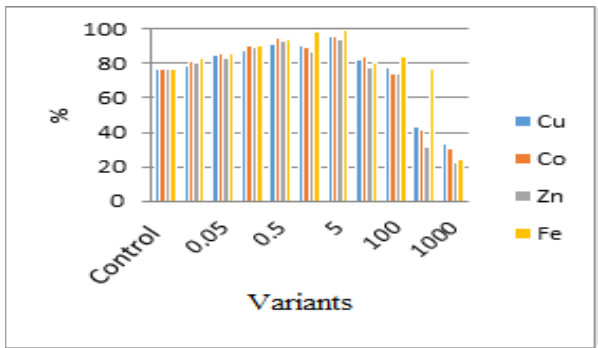

(a) nanoparticles size of $35-60 \mathrm{~nm}$

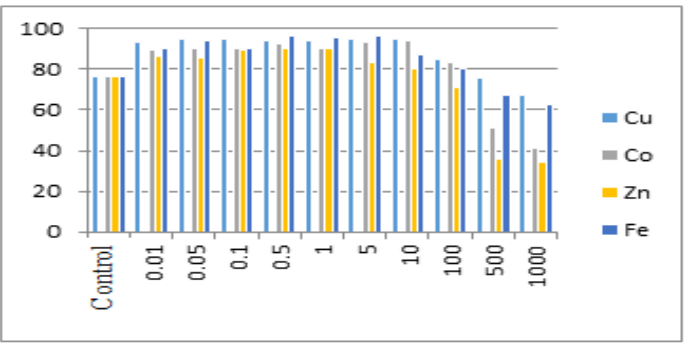

(b) nanoparticles size of up to $20 \mathrm{~nm}$

Fig. 1. The effect of nanoparticles on the germination energy of wheat seeds

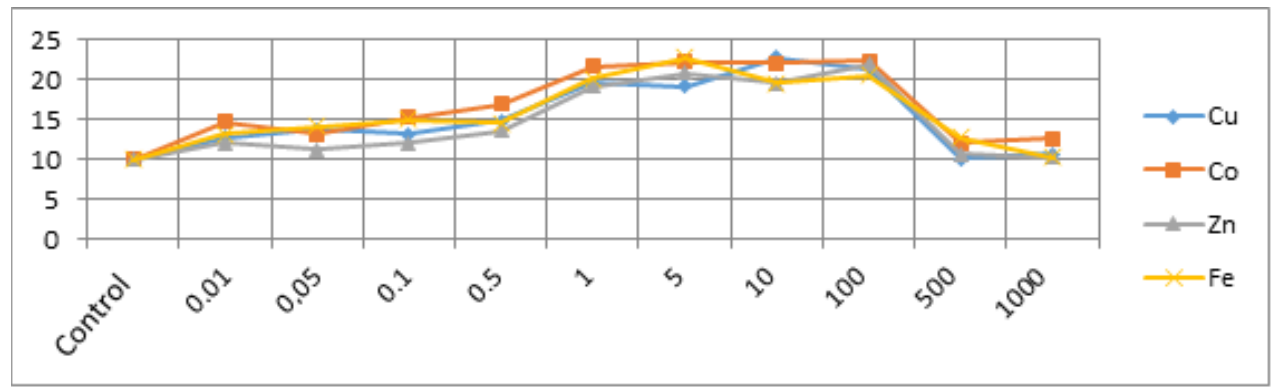

Fig. 2. The root length of 3-day wheat seedlings, nanoparticles sized $35-60 \mathrm{~nm}$ 


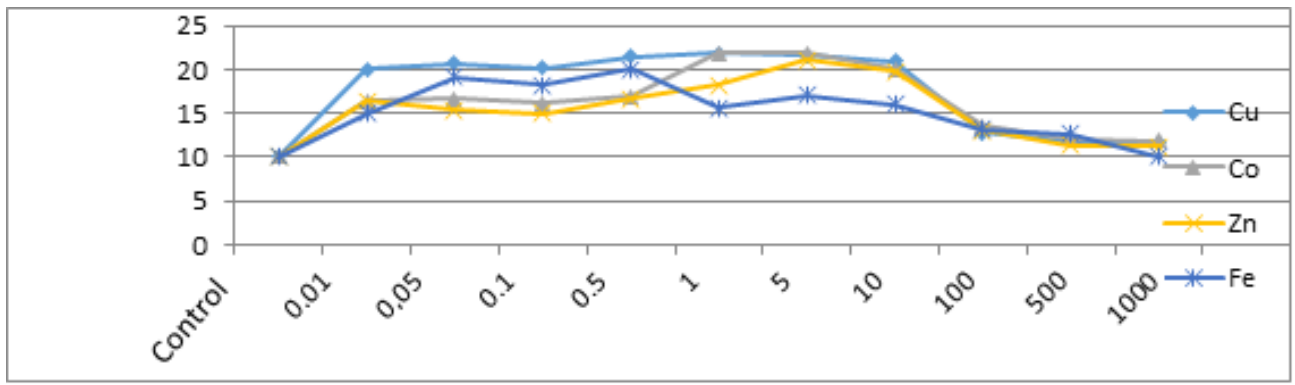

Fig. 3. The root length of 3-day wheat seedlings, nanoparticles sized up to $20 \mathrm{~nm}$

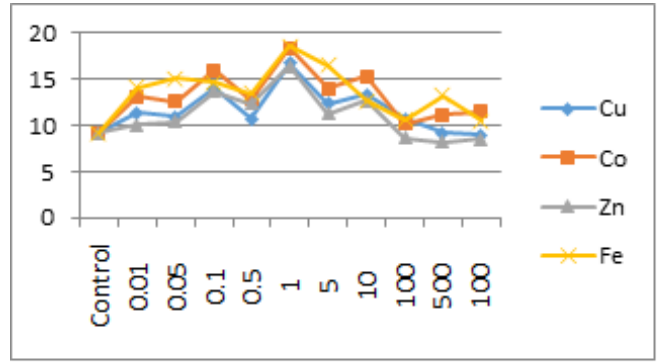

(a) nanoparticles size of $35-60 \mathrm{~nm}$

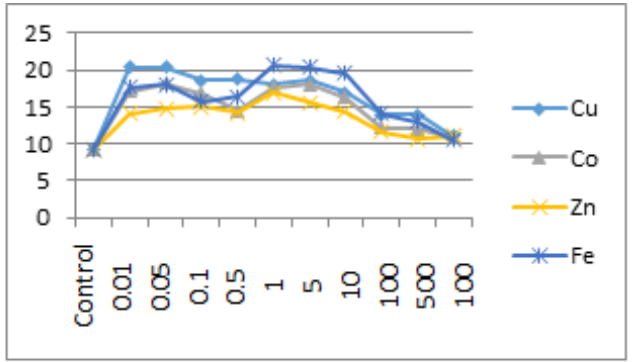

(b) nanoparticles size of up to $20 \mathrm{~nm}$

Fig. 4. The length of the shoot of 3-day wheat seedlings

The characteristics of metal nanoparticles, affecting their biological activity were determined (Table 1). Nanoparticles of up to $20 \mathrm{~nm}$ in size have higher solubility in aqueous solutions (Table 2), which is important for the rate of their interaction with living systems and the mechanism of their action.

Table 1. Characteristics of nanoparticles

\begin{tabular}{|c|c|c|c|c|}
\hline & $\mathrm{Cu}$ & $\mathrm{Co}$ & $\mathrm{Fe}$ & $\mathrm{Zn}$ \\
\hline $\begin{array}{l}\text { Particle size, } \\
\mathrm{nm}\end{array}$ & $24-63$ & $20-66$ & $25-68$ & $23-65$ \\
\hline $\begin{array}{l}\text { Solubility in } \\
\text { water, wt \% }\end{array}$ & Insoluble & Insoluble & Insoluble & Insoluble \\
\hline $\begin{array}{l}\text { Solubility in } \\
\text { physiological } \\
\text { solution, wt \% }\end{array}$ & $<1$ & $<1$ & $<1$ & $<1$ \\
\hline Charge & + & + & + & + \\
\hline $\begin{array}{l}\text { Aggregation } \\
\text { resistance }\end{array}$ & Low & Low & Low & Low \\
\hline $\begin{array}{l}\text { Hydrophobic } \\
\text { nature }\end{array}$ & + & + & + & + \\
\hline $\begin{array}{l}\text { Adhesion to } \\
\text { plant surfaces }\end{array}$ & $\begin{array}{l}\text { detected by } \\
\text { electron } \\
\text { microscopic } \\
\text { analysis }\end{array}$ & $\begin{array}{l}\text { detected by } \\
\text { electron } \\
\text { microscopic } \\
\text { analysis }\end{array}$ & $\begin{array}{l}\text { detected by } \\
\text { electron } \\
\text { microscopic } \\
\text { analysis }\end{array}$ & $\begin{array}{l}\text { detected by } \\
\text { electron } \\
\text { microscopic } \\
\text { analysis }\end{array}$ \\
\hline
\end{tabular}

Table 2. Solubility of nanoparticles with sizes of up to $20 \mathrm{~nm}$, wt \%

\begin{tabular}{|c|c|c|c|c|c|}
\hline Solvent & Time & $\mathrm{Cu}$ & $\mathrm{Fe}$ & $\mathrm{Zn}$ & $\mathrm{Co}$ \\
\hline \multirow{2}{*}{ Distilled water } & 6 hours & 2.0 & 2.2 & 2.0 & 2.3 \\
\cline { 2 - 6 } & 24 hours & 10.9 & 12.1 & 10.7 & 13.6 \\
\hline Physiological & 6 hours & 1.2 & 1.7 & 1.1 & 1.4 \\
\hline
\end{tabular}




\begin{tabular}{|l|l|l|l|l|l|}
\hline solution & 24 hours & 10.6 & 12.8 & 10.8 & 12.2 \\
\hline
\end{tabular}

Due to a large size for permeability through membranes metal nanoparticles with a size of 100-200 nm practically did not affect the growth and development of seeds on the 3rd day of contact in relation to the control. With an increase in the time of their action and concentrations (100-1000 g/t) morphophysiological parameters changed: the growth of wheat seedlings in laboratory conditions at a copper NP concentration of $100 \mathrm{~g} / \mathrm{t}$ increased. On the 7th day, the length of the shoots increased by $15 \%$ compared to the control, and the length of the root by $28 \%$. Here, bioaccumulation of NPs is possible, the response to which is changes leading to an increase in cell permeability. Thus, it makes no sense to talk about the LD effect, since the number of nanoparticles penetrating through the membrane proceeds at a low speed and is approximately the same.

Electron-microscopic methods did not show reliable accumulation of nanoparticles in plant tissues for all studied metals with a size of 20-200 nm up to a concentration of 1,000 $\mathrm{g} / \mathrm{t}$ (Figure 5). This is important for poorly soluble metal nanoparticles.

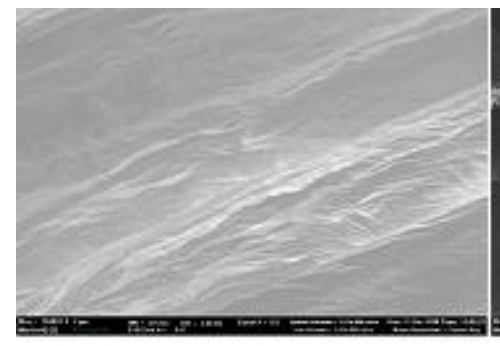

a

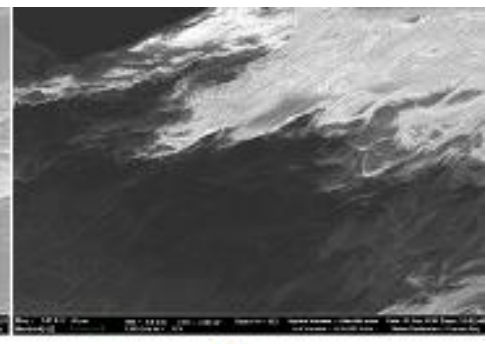

b

Fig. 5. Micrographs from a scanning microscope of the cell surface after 20 days of contact of seeds with suspensions of metal nanoparticles, 20-200 $\mathrm{nm}$ in size: a - seedlings, $\mathrm{b}$ - roots

Oxide nanoparticles sized $20-80 \mathrm{~nm}$ also pass through the cell membrane, but their action is different. Nanostructured metal oxides accumulate in the structure of plants. They form large aggregates in both shoots and roots, as proven by SEM and ETM, and inhibit physiological and biochemical processes in seedlings [9].

Thus, depending on their size, nanoparticles in contact with living systems can exhibit a certain biological activity and affect the metabolic processes of plants, realizing different mechanisms of their action. The physical-chemical activity of nanoparticles depends on the composition and morphology of the particles, as well as on the method of preparation [10, 11], but at the same size, the nanoparticles show the same biological activity, that is, the magnitude of the response signal is uniform.

For nanoparticles, a $\mathrm{pH}$ shift in biological fluids to the acidic region has been proven. The number of protons increases depending on the concentration and size of nanoparticles (Figure 6). If one considers that the $2 \mathrm{H}^{+}+2 \mathrm{e}^{-}$system is one of the factors of biological oxidation, then an increase in the number of protons increases the energy that is used for growth and development of plants. This refers to an increase in the permeability of cell membranes and the activity of enzymes and phytohormones. 


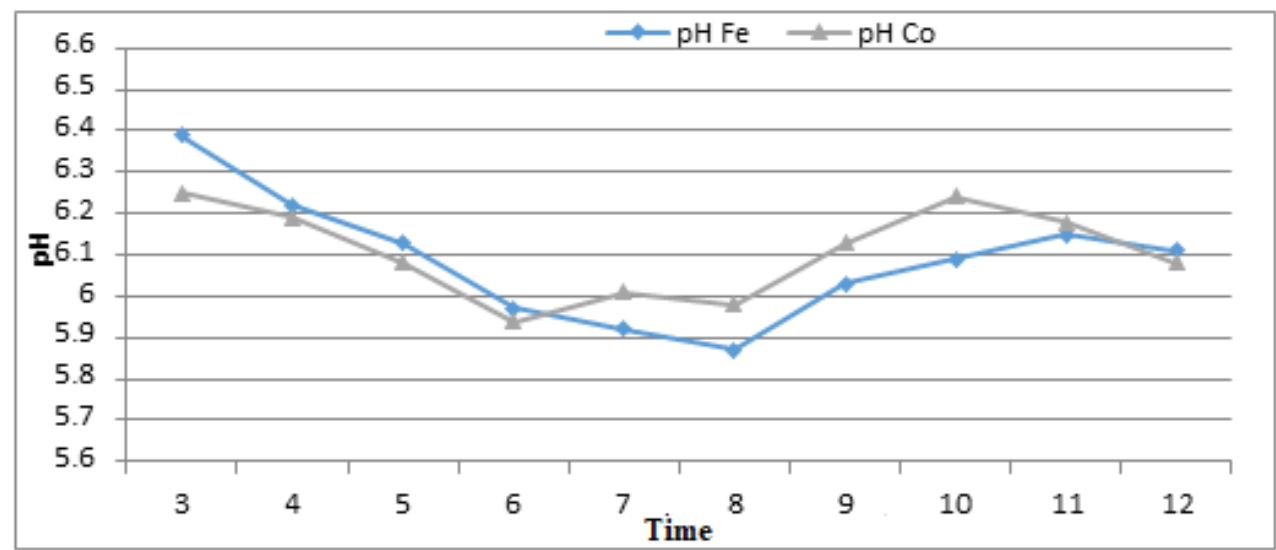

Fig. 6. Change in $\mathrm{pH}$ of nanostructured iron and cobalt in physiological solution

The content of hydrogen cations in a solution containing $100 \mathrm{~g} / \mathrm{t} \mathrm{Fe}$ increased 4.4 times (nanoparticles of 35-60 nm) and 15.5 times in a solution containing $10 \mathrm{~g} / \mathrm{t} \mathrm{Fe}$. Therefore, the activity of surface iron atoms is higher at a lower concentration and the biological activity is also greater. With an increase in the number of protons, the energy component increases, the growth and development of plants is more intensive. The content of hydrogen cations increased only 25 times for nanoparticles up to $20 \mathrm{~nm}$ in size at a concentration of $10 \mathrm{~g} / \mathrm{t} \mathrm{Fe}$ and it increased 28 times when a concentration of $0.01 \mathrm{~g} / \mathrm{t}$. A similar dependence is observed for cobalt nanoparticles.

There are known works on the influence of intracellular $\mathrm{pH}$. Such processes as transport through membranes, enzyme activity and control of enzymatic reactions depend on the $\mathrm{pH}$ value in the cell $[12,13]$. There are protein complexes for this, converting chemical energy into other types of it. Some part of the energy is expended for the directed movement of individual fragments through biological membranes. A significant part is used for ATP synthesis [14]. ATP synthase, which catalyzes the formation of ATP molecules, has a "proton potential" $\Delta \mu \mathrm{H}+160-220 \mathrm{mV}$. The transmembrane potential difference $\Delta \phi$ in plants is shunted due to the relatively high conductivity of thylakoid membranes for $\mathrm{Mg} 2+$, $\mathrm{K}+, \mathrm{Na}+, \mathrm{Cl}-$ ions. But due to the constant transmembrane flux of protons caused by the operation of the electron transport chain, a sufficiently high transmembrane difference $\Delta \mathrm{pH}$ can be maintained, which increases the physiological activity of plant germination and development.

The response of antioxidant enzymes: SOD, catalase and peroxidase to the action of nanostructured metals is different. But their values confirm the biological activity of metal nanoparticles within the range of up to $100 \mathrm{~nm}$. The activity of peroxidase increases at maximum morphophysiological parameters and decreases from a concentration of $500 \mathrm{~g} / \mathrm{t}$. At the same concentrations, the SOD and catalase values decreased, but at concentrations above $100 \mathrm{~g} / \mathrm{t}(20-60 \mathrm{~nm}$ ) and $10 \mathrm{~g} / \mathrm{t}$ (up to $20 \mathrm{~nm}$ ) it increased. The values of enzyme activity and the nature of their changes in shoots and roots are different, but they confirm the biological activity and development of plants within the given concentrations. The magnitude of the response signal of cellular structures depends on the concentration and size of nanoparticles.

Since nanoparticles are sources of additional amounts of protons that affect information triggering physiological and biochemical processes, they change the hormonal status of the cell. Thus, nanostructured particles are indirectly regulators of protein-synthesizing plant cells [15], that contributes to more active growth and development of plants.

The content of indoleacetic acid (IAA) increases in the concentration range $0.01-100 \mathrm{~g} / \mathrm{t}$ under the influence of nanoparticles of cobalt, iron, copper and to a lesser extent zinc. The 
efficiency of respiration in plant cells increases, stimulating the transfer of water and nutrients. The plants develop faster, while the activity of enzymes changes. For nanoparticles up to $20 \mathrm{~nm}$, a similar dependence is observed as in the case of particles with a size of 20-60 nm, but some increase in the activity of gibberellic acid (GA), cytokinins (CK) and IAA relative to the control at lower concentrations of 0.01-1.0 g/t is observed. The values of these deviations are greater than for nanoparticles sized 35-60 $\mathrm{nm}$ at a given concentration.

\section{Conclusion}

It is known that the pore diameter in the cell walls is $5-20 \mathrm{~nm}$, which makes it impossible for large aggregates to enter the cell. Nanoparticles with a size of 20-60 nm are biologically active and have the effect of "low doses" $[22,23]$. The cell membrane is covered with many receptors, which, under the influence of nanoparticles, transmit a signal to the cell space, the value of which depends on the size and concentration of particles. This signal can stimulate many physiological and biochemical reactions and can lead to the penetration of nanoparticles through endocytosis. During endocytosis, the plasma membrane, forming a hole structure, allows nanoparticles to penetrate into cells, which are further involved in metabolic processes. Depending on the properties of NPs, the activity of the synthesis of enzymes and phytohormones, in particular IAA, changes, which affects the growth and development of plants. The observed biological effects are caused by nanoparticles of the same size but different physical-chemical properties. Therefore, the reason is a certain regulatory signal entering biological systems, the intensity of which depends on the concentration of nanoparticles. Such a biological effect can correspond to universal information for many living systems, that is typical for membrane and supramolecular structures of the cell microenvironment. For oxides, accumulation is characteristic, which has a destructive effect on physiological and biochemical processes. For metal nanoparticles, in contrast to their nanostructured oxides, the accumulation has not been proven, but their permeability into the cell takes place, so one can speak about biocompatibility. The concentration of protons in the outer layer of the membrane increases. The return through ATP-ase leads to the synthesis of ATP, enzymes and phytohormones, that indirectly affects the synthesis of DNA. All this stimulates the processes of growth and development, allowing plants to realize their genetic potential and eliminate some adverse environmental impact.

\section{References}

1. M. Auffan, J. Rose, J-Y. Bottero, G.V. Lowry, J-P. Jolivet, M.R. Wiesner, Nanotechnology, 4, 634-641 (2009) https://doi.org/10.1038/nnano.2009.242

2. G.I. Churilov, S.D. Polischuk, M.V. Kutskir, D.G. Churilov, S.N. Borychev, Activators of Biochemical and Physiological Processes in Plants Based on Fine Humic Acids, IOP Conf. Ser.: Mater. Sci. Eng., 98 (2015)

3. Zh. Chen, H. Meng, H. Yuan, G. Xing, Ch. Chen, F. Zhao, Y. Wang, Ch. Zhang, Yu. Zhao, J. Radio, Nucl. Chem, 272(3), 599-603 (2007) doi: 10.1007/s10967-007-0631-1

4. A.L. Kursanov, Internal organization of physiological processes in plants, Scientist and audience (Moscow, Science, 1982)

5. D.R. Serrano, A. Lalatsa, M. Auxiliadora Dea-Ayuela, P.E. Bilbao-Ramos, N.L. Garrett, J. Moger, J. Guarro, J. Capilla, M. Paloma Ballesteros, A.G. Schätzlein, F. 
Bolás, J.J. Torrado, I.F. Uchegbu, Molecular Pharmaceutics, 12(2), 420-431 (2015) doi: $10.1021 / \mathrm{mp} 500527 \mathrm{x}$

6. A.A. Nosenko, S.I. Polovneva, Izvestiya vuzov. Applied chemistry and biotechnology, 7(2), 113-121 (2017)

7. G.V. Vekilova, A.N. Ivanov, Yu.D. Yagodkin, Diffraction and microscopic methods and devices for the analysis of nanoparticles and nanomaterials (Moscow, MISiS, 2009)

8. Ma X, Gurung A., X. Deng, Science of the Total Environment, 443, 844-849 (2013)

9. I.A. Stepanova, S.D. Polischuk, D.G. Churilov, V.V. Churilova, I.V. Obidina, G.I. Churilov, Herald of Ryazan State Agrotechnological University Named after P.A. Kostychev, 1 (41), 62-68 (2019)

10. D.G. Churilov, Biological activity of nanomaterials depending on the method of their production. Innovative development of the modern agro-industrial complex of Russia. Materials of the National Scientific and Practical Conference, 233-240 (2016)

11. D. Churilov, V. Churilova, I. Stepanova, S. Polischuk, A. Gusev, O. Zakharova, I. Arapov, G. Churilov, Size-dependent biological effects of copper nanopowders on mustard seedlings, IOP Conf. Series: Earth and Environmental Science, 012008, 392 (2019) doi:10.1088/1755-1315/392/1/012008

12. A.Yu. Aleksanyan, A.N. Podobaev, I.I. Reformatskaya, V.D. Kiselev, Regularities of the initial stages of iron ionization in neutral environments, Condensed matter and interphase boundaries, 7(3), 329-334 (2005)

13. 18. O.N. Kulaeva, Hormonal regulation of physiological processes in plants at the level of RNA and protein (Moscow, Science, 1982)

14. Yu.M. Romanovskiy, A.N. Tikhonov, Advances in physical sciences, 180(9), 932-956 (2010)

15. S.V. Zaitsev, A.M. Efanov, L.A. Sazonov, Chem. J., 5, 28-33 (1999) 